\title{
The Role of Maternal Breast Milk in Preventing Infantile Diarrhea in the Developing World
}

\author{
Christie G. Turin • Theresa J. Ochoa
}

Published online: 15 March 2014

(C) Springer International Publishing AG 2014

\begin{abstract}
Multiple interventions have been designed to decrease mortality and disability in children. Among these, breastfeeding is the most cost-effective intervention for protecting children against diarrhea and all causes of mortality. Human milk is uniquely suited to the human infant, both in its nutritional composition and in the nonnutritive bioactive factors that promote survival and healthy development. Suboptimal breastfeeding has been linked with numerous adverse child health outcomes including increased incidence of diarrhea and pneumonia. This review provides an update regarding recent studies on the effect of breastfeeding on diarrhea morbidity and mortality in children in developing countries, describes major human milk components responsible for this protective effect (oligosaccharides, secretory immunoglobulins, lactoferrin, bacterial microbiota, etc.), and highlights areas for future research in this topic. Breastfeeding promotion remains an intervention of enormous public health potential to decrease global mortality and promote better growth and neurodevelopment in children.
\end{abstract}

Keywords Breastfeeding $\cdot$ Breast milk $\cdot$ Human milk . Diarrhea · Gastroenteritis · Infants · Children · Mortality · Morbidity $\cdot$ Developing countries $\cdot$ Oligosaccharides · Antibodies $\cdot$ Lactoferrin $\cdot$ Protective factors $\cdot$ Enteric

\footnotetext{
C. G. Turin · T. J. Ochoa $(\bowtie)$

Department of Pediatrics, Instituto de Medicina Tropical "Alexander von Humboldt”, Universidad Peruana Cayetano Heredia, Av.

Honorio Delgado 430, San Martin de Porras Lima 33, Peru

e-mail: Theresa.J.Ochoa@uth.tmc.edu

C. G. Turin

e-mail: christie.turin@upch.pe

T. J. Ochoa

Center for Infectious Diseases, University of Texas School of Public Health, Houston, TX, USA
}

pathogens $\cdot$ Nutrition $\cdot$ Tropical medicine $\cdot$ GI infections . Bacterial tropical medicine

\section{Introduction}

Globally, 7.6 million children less than 5 years of age died in 2010; $64 \%$ (4.8 million) were attributable to infectious causes. The leading causes of death beyond the neonatal period are pneumonia and diarrhea. Diarrhea accounts for $10.5 \%$ of all deaths ( 0.8 million deaths, range: 0.6 to 1.2 million) [1•]; a significant burden of diarrhea mortality is concentrated among the poorest populations in countries of sub-Saharan Africa and South Asia [2]. Despite the reduction in mortality in recent years, diarrhea continues to be one of the main preventable causes of death in children. In addition to causing high mortality, recurrent or persistent diarrhea has serious long term effects on growth, nutrition and cognition [3].

Multiple preventive and therapeutic interventions have been designed to decrease mortality and disability in children. Among these, early and exclusive breastfeeding is one of the most important interventions to reduce neonatal and infant mortality [4]. Breastfeeding is widely promoted [5•] and is the most cost-effective intervention for protecting children against diarrhea and all causes of mortality [6]. Human breast milk helps protect infants by serving as a source of nutrition uncontaminated by environmental pathogens in addition to the direct protection due to its multiple anti-microbial, antiinflammatory and immunoregulatory components [7].

This review gives an update regarding recent studies on the effect of breastfeeding on diarrhea morbidity and mortality in children in developing countries, describes the human milk components responsible for this protective effect, and highlights areas for future research in this topic. 


\section{Effect of Breastfeeding on Diarrhea Morbidity and Mortality}

The benefits of breastfeeding on infant and child morbidity and mortality are well documented, with observational studies dating back to the 1960s. Breastfeeding demonstrates a doseresponse relationship of protection against diarrheal disease morbidity and mortality in infancy. Exclusive breastfeeding, defined as feeding only human milk with no other liquids or foods, is known to offer maximum protection against diarrhea to infants younger than 6 months of age, whereas partial breastfeeding offers intermediate protection compared with no breastfeeding [7]. Recently, Lamberti et al. analyzed the effect of suboptimal breastfeeding on diarrhea morbidity and mortality, based on review of 18 studies from developing countries published from 1980 to 2009 [8••]. They found that not breast feeding was associated with a $165 \%$ [relative risk (RR) 2.65, $95 \%$ confidence interval (CI) 1.72-4.07] increase in diarrhea incidence in infants aged 0-5 months, a $32 \%(\mathrm{RR}$ : $1.32,95 \%$ CI 1.06-1.63) increase in those aged 6-11 months, and a $32 \%$ (RR: 1.32, $95 \%$ CI 1.06-1.63) increase in those aged 12-23 months. Not breastfeeding was also associated with a $952 \%$ (RR: 10.52, $95 \%$ CI 2.79-49.6) increase in diarrhea mortality as compared to exclusive breastfeeding in infants aged 0-5 months of age, a $47 \%$ (RR: 1.47, $95 \% \mathrm{CI}$ 0.67-3.25) increase as compared to any breastfeeding practice in those aged 6-11 months, and a $157 \%$ (RR: $2.57,95 \% \mathrm{CI}$ $1.10-6.01)$ increase in those aged 12-23 months.

A prospective observational cohort of 1,677 infants followed from birth to 12 months of age in slum areas of Dhaka in Bangladesh found that very few infants were not breastfed; however, the prevalence of exclusively breastfeeding at enrollment was only $6 \%$. The proportion of partially breastfed infants increased with age [9]. Compared with exclusive breastfeeding in the first few months of life, partial or no breastfeeding was associated with a 2.23-fold higher risk of infant deaths resulting from all causes and higher risk of deaths attributable to acute respiratory infections (2.40-fold) and diarrhea (3.94-fold), respectively. Study estimates indicate that infant mortality could be reduced by almost one-third if the prevalence of exclusive breastfeeding in the first 4 months of life could be raised to $\sim 80 \%$.

The Global Burden of Diseases, Injuries, and Risk Factors Study 2010 (GBD 2010) ranked suboptimal (non-exclusive or discontinued) breastfeeding as the second largest risk factor for children under 5 years, accounting for 47.5 million Disability Adjusted Life Years (DALYs) lost in 2010. The highest proportion of disease burden associated with suboptimal breastfeeding was clustered in regions of sub-Saharan Africa where childhood morbidity and mortality are highest [10•]. Black et al. also found an increased risk of mortality in children younger than 2 years old due to suboptimal breastfeeding, which is responsible for 804,000 deaths in
$2011,11.6 \%$ of total deaths of children under 5 years old $[11 \bullet \bullet$.

A recent study estimated the prevalence of suboptimal breastfeeding in 137 developing countries using data collected from 1990 to 2010 [12••]. These estimates were compared against WHO infant feeding recommendations and combined with effect sizes from existing literature to estimate associated disease burden using a standard comparative risk assessment approach. In 2010, the prevalence of exclusive breastfeeding ranged from $3 \%$ to $77 \%$. The proportion of DALYs attributable to breastfeeding was $7.6 \%$ worldwide and as high as $20 \%$ in some countries. Absence of breastfeeding is a leading childhood risk factor in developing countries and ranks higher than lack of a safe water supply and sanitation.

All these studies support the current WHO recommendation for exclusive breastfeeding during the first 6 months of life as a key child survival intervention and highlight the importance of breastfeeding to protect against diarrheaspecific morbidity and mortality throughout the first 2 years of life [13].

\section{Breastfeeding Promotion}

Despite the evidence that supports the protective effect of human milk on preventing diarrhea, pneumonia and overall mortality, the rates of breastfeeding are below WHO recommendations in many developing countries [12••]. Improvements in breastfeeding practices can be achieved through various educational and promotional strategies. Pediatricians play a critical role by supporting and motivating a successful mother-infant breastfeeding dyad [14].

A recent review of 110 randomized controlled trials and quasi-experimental studies found that rates of exclusive breastfeeding increased significantly because of breastfeeding promotional interventions: $43 \%$ (RR: 1.43, $95 \%$ CI: 1.19 1.42 ) at 1 day, $30 \%$ (RR: $1.30,95 \%$ CI: $1.19-1.42$ ) at 0 1 months, and $90 \%$ (RR: $1.90,95 \%$ CI: $1.54-2.34$ ) at $1-$ 6 months; rates of no breastfeeding decreased by $32 \%$ (RR: 0.68, $95 \%$ CI: $0.54-0.87$ ) at 1 day, $30 \%$ (RR: $0.70,95 \%$ CI: $0.62-0.80$ ) at $0-1$ month, and $18 \%$ (RR: $0.82,95 \%$ CI: $0.77-$ 0.89 ) for $1-6$ months. Combining individual and group counseling appeared to be more effective than either technique alone [15•].

Imdad et al. analyzed the effect of breastfeeding promotion reviewing 53 studies and found that there was a significant $43 \%$ (RR: 1.43, $95 \%$ CI: 1.28-1.60) increase in exclusive breastfeeding rate at 4-6 weeks, with an $89 \%$ increase in developing countries and a $137 \%$ increase at 6 months postpartum, with a six-fold increased incidence in developing countries [16]. Overall, in developing countries, facility and combined facility-based and community-based interventions led to greater breastfeeding rates, with greater effects on promotion and support interventions, than routine care [5•]. 
Breastfeeding promotion remains an intervention of enormous public health potential. It is one of the most costeffective child health interventions currently available and does not require extensive health system infrastructure. These characteristics, along with the large disease burden associated with suboptimal breastfeeding, indicate that breastfeeding promotion has the potential to improve child health outcomes $[12 \bullet \bullet$.

There are few and specific medical conditions that contraindicate absolutely breastfeeding, including some metabolic disorders and infectious diseases [17] [18]. Among infections, the only two conditions with enough evidence that support avoidance of breastfeeding are infection with human immunodeficiency virus (HIV 1 or 2) [19] and human T-cell lymphotrophic virus (HTLV I or II) [20].

\section{Protective Components of Human Milk}

Human milk is uniquely suited to the human infant, both in its nutritional composition and in the nonnutritive bioactive factors that promote survival and healthy development $[21 \bullet \bullet]$. Multiple immunologic factors produced by the mother's acquired and innate immune systems are transported to the infant through human milk. In addition to bioactive carbohydrates, proteins and lipids, human milk has cells, cytokines, chemokines, growth factors, hormones and bacteria [21••]. Many of these factors have been associated with a protective role against infections in children, including oligosaccharides, glycoconjugates (i.e., secretory immunoglobulins, lactoferrin, $\alpha$ lactalbumin, lysozyme, mucins) and bacterial microbiota (Table 1). Here we will summarize current evidence on the main human milk protective factors.

\section{Oligosaccharides}

The human milk metabolome is composed of hundreds of structurally different oligosaccharides (HMO) [22], which are unconjugated complex glycans. All HMO contain a lactose molecule at their reducing end, which can be fucosylated or sialylated; the oligosaccharides most commonly found in human milk are the fucosylate [23••]. Fucosylated HMO vary on a genetic basis related to the mother's secretor and Lewis blood group system [24]. The type of HMO that predominates in breast milk is also affected by the stage of lactation: the ratio of $\alpha 1,2$-linked fucosyloligosaccharides to $\alpha 1,3-$ and $\alpha 1,4$ linked declines at older age [25].

HMO are not digestible by humans - over $90 \%$ of them can be recovered in infant's stools and less than $1 \%$ are lost in the urine. Therefore, they stay at the gut lumen where it appears their major impact, which is protection against enteric pathogens. Human milk glycobiome can act as prebiotics [26]; HMO play an important role as prebiotics by stimulating the gut colonization with beneficial microbes [23••]. In addition, some of them have a similar structure to specific receptors on enterocyte cell surfaces; therefore, they prevent binding of some specific pathogens to the cells, inhibiting the host's infection [24]. This effect has been described for many viruses, bacteria and parasites.

Noroviruses, members of the calicivirus family, are an important cause of diarrhea in infants. Diarrhea due to norovirus occurs less often in infants of mothers with higher levels of lacto-N-difucohexaose (an $\alpha 1,2$-linked fucosyloligosaccharide) in their milk [24]. HMO may protect against this virus by blocking the binding to the histo-blood group antigen receptors [24].

In vitro studies have shown HMO protection against $\mathrm{Cam}$ pylobacter jejuni by reducing surface attachment [27], which was also demonstrated in a descriptive study with 93 motherinfant pairs [28]. Morrow et al. found that the rates of $C$. jejuni diarrhea decreased in infants as the percentage of 2 'fucosyloligosaccharide in human milk increased. Similarly, they inhibit adhesion of E. coli, Salmonella fyris and Vibrio cholera to epithelial cells [29]. Additional studies have demonstrated protection against $E$. coli in vitro by inhibiting the bacterium heat stable enterotoxin [25]. In vitro, HMO protects against Entamoeba histolytica infection by binding to Gal/ GalNAc and blocking the parasite attachment [30].

\section{Secretory Antibodies}

Lactating mammary glands are part of the secretory immune system. IgA antibodies in breast milk reflect prior antigenic stimulation of gut-associated lymphoid tissue (GALT) and nasopharynx-associated lymphoid tissue (NALT) such as the tonsils (Fig. 1). Breast milk antibodies are thus highly targeted against infectious agents and other exogenous antigens in the mother's environment, which are those likely to be encountered by the infant [31].

Secretory immunoglobulin A ( $\operatorname{sg} A)$ is the main immunoglobulin isotype in colostrum; it represents over $90 \%$ of the immunoglobulin present. Milk also contains $\operatorname{IgM}$ and $\operatorname{IgG}$, the latter becoming more abundant in later lactation $[21 \bullet \bullet]$. Concentrations of sIgA in human milk are highest in colostrum, decrease during the first month postpartum, and tend to remain stable over the remaining course of lactation. It is resistant to degradation by acid or proteolysis and generally is not absorbed from the gastrointestinal tract; thus, it is available to act at the mucosal surface of the intestine where it plays its major protective role by neutralizing bacteria, viruses and toxins $[32 \bullet \bullet]$.

The secretory antibodies found in human milk vary in quantities, depending on the exposure history of the mother. Specific antibodies most commonly identified in human milk are those targeted against the pathogens 
Table 1 Protective human milk components against enteropathogens
*For specific pathogens studied. EPEC, Enteropathogenic E. coli; EHEC, Enterohemorrhagic E. coli; STEC, Shiga toxin-producing E. coli; ETEC, Enterotoxigenic E. coli; EAEC, Enteroaggregative E. coli; LPS, lipopolysaccharide; $N K$, natural killer

\begin{tabular}{|c|c|c|}
\hline Component & Antimicrobial mechanisms & Affected enteropathogens* \\
\hline \multicolumn{3}{|l|}{ Cells } \\
\hline Macrophages & Activates T-cell, phagocytosis & \multirow{4}{*}{ Non-specific target } \\
\hline Mast cells & $\begin{array}{l}\text { Produces and releases substances } \\
\text { to damage pathogens }\end{array}$ & \\
\hline NK lymphocytes & Phagocytosis & \\
\hline \multicolumn{2}{|l|}{ Immunoglobulins } & \\
\hline IgG & $\begin{array}{l}\text { Activates phagocytosis } \\
\text { (IgG1, IgG2, IgG3) }\end{array}$ & Non-specific target \\
\hline $\operatorname{IgA} / \operatorname{sIg} \mathrm{A}$ & $\begin{array}{l}\text { Neutralizes bacteria, viruses and } \\
\text { toxins via Fab-mediated } \\
\text { mechanism } \\
\text { Inhibits pathogens adhesion by } \\
\text { forming potential-binding } \\
\text { epitopes }\end{array}$ & $\begin{array}{l}\text { EPEC, STEC, EHEC, Vibrio cholerae, } \\
\text { Campylobacter jejuni, } \\
\text { Shigella, Salmonella, Giardia lamblia, } \\
\text { C. difficile, H. pylori, Cryptosporidium, } \\
\text { E. histolytica }\end{array}$ \\
\hline \multicolumn{3}{|l|}{ Glycans } \\
\hline Lactoferrin & $\begin{array}{l}\text { Chelates iron } \\
\text { Inhibits pathogen adhesion, binds } \\
\text { LPS of Gram negative bacteria } \\
\text { Induces degradation of invasion } \\
\text { plasmid antigens } \\
\text { Disrupts the integrity of the } \\
\text { bacteria membrane } \\
\text { Anti-inflammatory } \\
\text { Immunomodulatory }\end{array}$ & $\begin{array}{l}\text { ETEC, STEC, EPEC, EAEC, Shigella } \\
\text { flexneri, Salmonella typhimurium, } \\
\text { Salmonella enterica, Rotavirus }\end{array}$ \\
\hline Lactadherin & Inhibits pathogen adhesion & Rotavirus \\
\hline Oligosaccharides & $\begin{array}{l}\text { Act as prebiotics } \\
\text { Inhibits pathogen adhesion } \\
\text { Anti-inflammatory } \\
\text { Immunomodulatory }\end{array}$ & $\begin{array}{l}\text { EPEC, ETEC, Shigella spp., Salmonella } \\
\text { fyris, Giardia lamblia, Campylobacter } \\
\text { jejuni, Vibrio cholerae, Norovirus, } \\
\text { Rotavirus }\end{array}$ \\
\hline Hyaluronan & $\begin{array}{l}\text { Preserves of the epithelial } \\
\text { barrier integrity }\end{array}$ & Salmonella enterica \\
\hline Mucins: MUC1 and MUC4 & Inhibits pathogen adhesion & $\begin{array}{l}\text { Salmonella enterica, Escherichia } \\
\text { coli, Rotavirus, Norovirus }\end{array}$ \\
\hline K-casein & $\begin{array}{l}\text { Promotes the growth of } \\
\text { microbiota } \\
\text { Inhibits pathogen adhesion }\end{array}$ & Helicobacter pylori \\
\hline Ganglioside GM1 & Binds toxins & ETEC, Vibrio cholerae, Shigella \\
\hline Ganglioside GM3 & Binds toxins & EPEC \\
\hline \multicolumn{3}{|l|}{ Enzymes } \\
\hline Lysozyme & $\begin{array}{l}\text { Disrupts the integrity of the } \\
\text { bacteria wall }\end{array}$ & Escherichia coli, Salmonella \\
\hline Lactoperoxidase & $\begin{array}{l}\text { Produces intermediate } \\
\text { metabolites with antimicrobial } \\
\text { properties }\end{array}$ & Non-specific target \\
\hline \multicolumn{3}{|l|}{ Probiotics } \\
\hline Bifidobacterium & $\begin{array}{l}\text { Acidifies the gut } \\
\text { Excretes substances to inhibit } \\
\text { pathogens growth }\end{array}$ & Non-specific target \\
\hline & Inhibits pathogen adhesion & \\
\hline
\end{tabular}

endemic in the mother's environment; therefore, their concentrations differ between populations. Protection by human milk antibodies against specific virulence factors of enteric pathogens have been described for Vibrio cholera, Campylobacter jejuni, enteropathogenic E. coli (EPEC), Shigella, Salmonella, Giardia lamblia, among others. Studies of protection by human milk antibodies against rotavirus have produced variable results [7]. 
Fig. 1 Integration of mucosal immunity between mother and the newborn. Migration of effector B cells from the gutassociated lymphoid tissue (GALT) via lymph and peripheral blood to the lactating mammary gland. The distribution of B cells beyond the gut (arrows) is crucial for local production in breast milk of sIgA antibodies specific for enteric and airway microorganisms (modified from Brandtzaeg P, 2010) [31]. There is also transmission of organisms/ bioactive compounds from the child to the mother which induces responses from the mother that are specific to the child's needs (two-way path) [54]

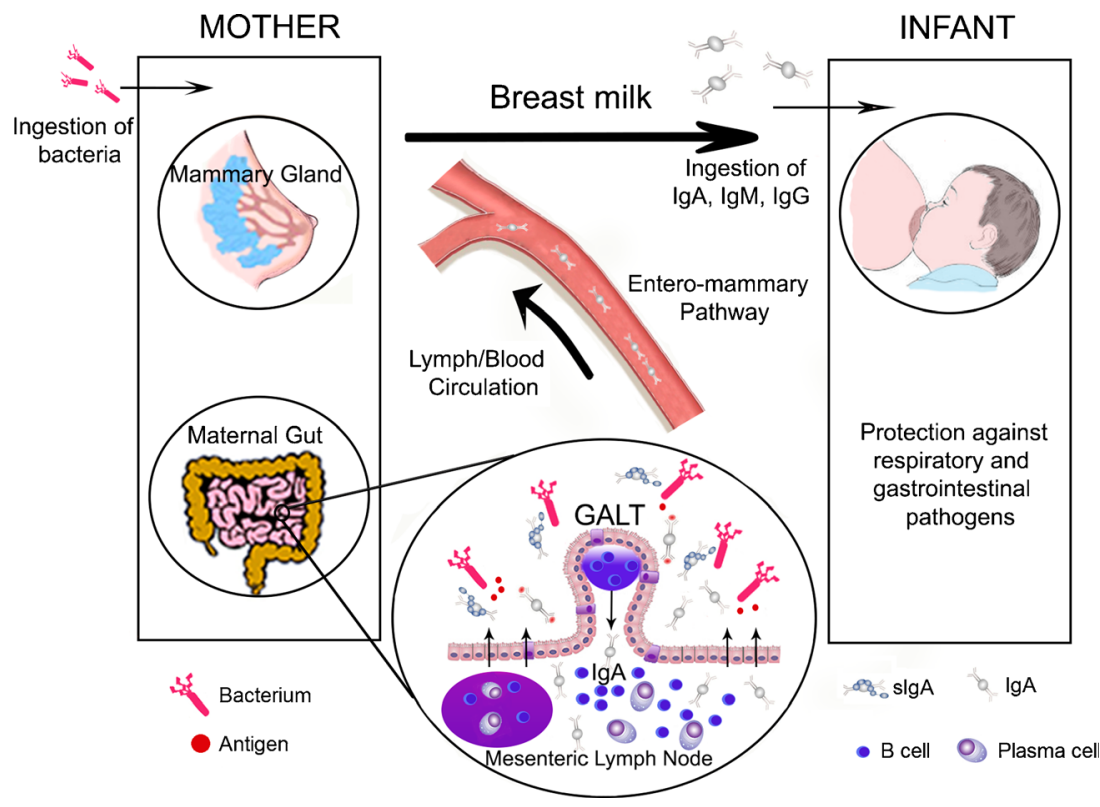

Recently, we have evaluated 76 colostrum samples of puerperal women living in Lima, Peru for the presence of SIgA against 10 major proteins secreted by the type three secretion system (T3SS) of Salmonella, Shigella and EPEC [33]. We found antibodies against each T3SS protein in 41 to $99 \%$ of samples. The extraordinarily high frequency of antibodies in colostrum detected in this study against these multiple enteric pathogens, shows evidence of immunological memory and prior maternal exposure to these bacteria. This study provides insight into the range of antibodies consumed by infants in a developing country setting, in addition to their possible protective role against infection.

A prospective cohort study in Bangladesh found protection against infection with Cryptosporidium and Entamoaeba histolytica, two important enteric pathogens in developing countires, by parasite-specific immunoglobulin A in breast milk. This study is an additional proof that specific passive immunity is transmitted from mother to child in endemic areas [34].

\section{Lactoferrin}

Lactoferrin is the second most abundant protein in human milk; the highest concentration is in colostrum $(\sim 10 \mathrm{mg} / \mathrm{mL})$ [35]. It is an iron binding glycoprotein with multiple antimicrobial, anti-inflammatory and immunomodulatory properties [36・*]. The antimicrobial activity is related to its ability to sequester iron which is essential for bacterial growth, conferring a bacteriostatic effect [37]. In addition, lactoferrin is a positively charged molecule; this cationic character is responsible for lactoferrin's ability to bind different cell types, nucleic acids, and a variety of proteins and other molecules [38]. Lactoferrin binds to the lipopolysaccharide (LPS) of the
Gram negative bacterial cell surface, disrupting the bacteria cell membrane.

Lactoferrin decreases the ability of enteric pathogens to adhere to and invade mammalian cells by binding and degrading specific virulence proteins. This effect has been documented in vitro for Shigella, Salmonella, enteropathogenic $E$. coli (EPEC), enteroaggregative E. coli (EAEC), shiga toxin-producing E. coli (STEC), as well as some enteric viruses (rotavirus, calicivirus) and parasites (Giardia, Entamoeba histolytica) [39]. Moreover, exposure of bovine lactoferrin to pepsin (e.g., in gastric secretions) releases an $\mathrm{N}$ terminus peptide fragment called lactoferricin, that is bactericidal in vitro for Gram negative and Gram positive bacteria and yeast [37].

Multiple animal models have been used to demonstrate lactoferrin protective effect against enteric infections. Lactoferrin protects rabbits form Shigella flexneri-induced inflammatory enteritis [40] and protects against Salmonella ser. Typhimurium infection in mice, reducing the severity, mortality and the degree of inflammation [41]; it decreases cholera toxin induced fluid accumulation in the mouse ileal loop by decreasing the binding of the toxin with its receptor [42].

Lactoferrin is produced by other mammals. Bovine lactoferrin has $70 \%$ amino acid homology to human lactoferrin and varies in the number of glycosylated sites [43]. Recombinant human lactoferrin is produced in different systems (fungus, rice, cows, goats, etc); the amino acid sequence is the same; however, the glycosylation pattern is different. Despite some structural differences, all these lactoferrin types seem to preserve their functional properties [38].

In a recent review of the literature, we identified 19 published clinical studies of human and bovine lactoferrin 
conducted in children [44•]. Bovine lactoferrin is the most common type used in the majority of trials; the doses are variable and usually are chosen based on the average concentration received by a breastfed infant according to age. Among these, three studies describe the effect of lactoferrin on enteric infections, plus one additional study published afterwards. Egashira et al. in Japan studied 298 children receiving lactoferrin containing products; although there was no difference in the incidence of rotaviral gastroenteritis, the duration of episodes and the frequency and duration of vomiting were markedly decreased in the lactoferrin group [45]. A study in 140 Peruvian children with acute watery diarrhea and dehydration showed that adding recombinant human lactoferrin and lysozyme to oral rehydration solution reduced the duration (3.67 vs. 5.21 days) and recurrence of diarrhea [46]. A small pilot community-based controlled trial comparing twice daily oral supplementation with bovine lactoferrin versus placebo in 52 Peruvian children, showed that the lactoferrin group had less Giardia-positive samples per child and better height-for-age z-score, as well as a trend toward shorter duration of diarrheal episodes [47]. We have recently completed a randomized double blinded study of bovine lactoferrin supplementation on the prevention of diarrhea in 555 children 12 to 24 months of age in peri-urban communities of Lima, Peru [48•]. Although there was no decrease in diarrhea incidence (5.4 vs. 5.2 episodes/child/year for lactoferrin and placebo, respectively; $\mathrm{p}=0.375)$, the longitudinal prevalence $(6.6 \%$ vs. $7.0 \%, p=0.017)$, the median duration of episodes ( $4.8 \mathrm{vs}$. 5.3 days, $\mathrm{p}=0.046$ ), the proportion of episodes with moderate or severe dehydration $(1.0 \%$ vs. $2.6 \%, p=0.045)$ and liquid stools load (95.0 vs. 98.6 liquid stools/child/year, $\mathrm{p}<0.001$ ) were decreased with lactoferrin. Bovine lactoferrin was administered twice daily for 6 months; there were no adverse events related to the intervention in the more than 75,000 lactoferrin doses administered. Only a single dose was evaluated in this study so that it is unclear whether a higher dose might have had greater benefit. Although this study makes it unlikely that bovine lactoferrin can have a major role in prevention of diarrhea in children in the second year of life, it leaves open the possibility that lactoferrin could have a role in younger infants or as an adjunct to other measures in treatment of diarrheal episodes, especially for the treatment of prolonged and persistent diarrhea, which are associated with malnutrition and impaired neurodevelopment.

\section{Hyaluronan}

Hyaluronan is a glycosaminoglycan present in milk, which does not possess a protein core. Recent in vitro studies have demonstrated that treatment of colonic epithelial cells with human milk hyaluronan results in dose-dependent induction of defensins, which are antimicrobial human peptides that play an important role in the preservation of the epithelial barrier integrity against microbial challenges. In addition, treatment of cultured colonic epithelial cells with hyaluronan decreases Salmonella typhimurium infection [49].

\section{K-Casein}

K-casein accounts for $25 \%$ of total casein in human milk and due to its glycosylated moieties; it is a major contributor to the anti-infective property. In the gut's lumen, k-casein forms new molecules (para-k-casein and caseinomacropeptide), which act as prebiotics, and promotes microbiota growth [32••]. Also, it inhibits the adhesion of pathogens to the epithelial cell surface in the gastrointestinal and respiratory tracts.

\section{Mucins}

Mucins prevent infection of gastrointestinal and respiratory tracts by decreasing the adhesion of pathogens to the cell surface. There are two types of mucins that have been the focus of research, MUC1 and MUC4 [32••]. A recent study showed that these mucins could inhibit Salmonella enterica serovar Typhimurium invasion of human epithelial cells in vitro [50]. Sialylated human milk mucin inhibited rotavirus replication in tissue culture and prevented rotavirus gastroenteritis in a mouse model, and blocked the adhesion of recombinant norovirus-like particles [32••]. More evidence is needed to confirm its beneficial effect as a prophylactic agent.

\section{Lactadherin}

Lactadherin is a mucin-associated sialylated glycoprotein found in the milk fat globule membrane. The antipathogenic properties of lactadherin have been associated mainly with its protection against rotavirus. In a cohort of 200 infants in Mexico, the incidence and symptoms of rotavirus infections was studied and compared with the lactadherin concentration in their mothers' breast milk. Among infected infants, those who were fed milk containing high levels of lactadherin remained asymptomatic, whereas severe diarrhea resulted when infants were fed milk containing low levels of lactadherin [51]. Lactadherin inhibits the ability of rotavirus to infect epithelial cells [24]. This is postulated to be the major milk component that prevents rotavirus infection; anti-rotavirus antibodies play a secondary role in neutralizing the virus activity [52].

\section{Probiotics}

Intestinal microflora of breastfed infants is composed of skin and enteric bacteria, mainly Lactobacillus bifidus (or Bifidobacterium bifidum). These bacteria have the ability to acidify the gut and decrease the probability of infection by enteric pathogens [24], produce antimicrobial compounds 
[53], and could be involved in enhancing intestinal barrier protection [54]. Breast milk is a source of bacterial communities transferred from the mother to the child and from the child to the mother during suckling (two-way path) [53] [54]; these bacteria colonize the neonatal gut [55]. Among these bacterial microbiota, Lactobacillus [56] and Bifidobacteria [57] species are considered probiotics.

\section{Variation in Human Milk Components}

Breast milk components vary depending on the stage of lactation, gestational age and some other maternal factors, including genetic polymorphisms. Colostrum, the first breast milk fluid produced in the first 5 days postpartum, is rich in proteins, such as lactoferrin, immunoglobulins and developmental factors; its main function is to protect the newborn from infections and promote gut maturation $[21 \bullet \cdot]$. One study found the highest immunoglobulin A concentration in the third day after delivery [58]. Transitional milk produced from the sixth day to the second week postpartum is an intermediate fluid with some protective and nutritional properties. In contrast, mature milk (after the fourth week postpartum) has a higher concentration of lipids and lactose, and lower concentration of proteins $[21 \bullet \bullet]$. Beyond week 12, the immunoglobulin levels decrease gradually [58].

Gestational age also affects human milk composition: protein levels are higher in mothers who had a premature delivery (i.e., higher lactoferrin concentrations); as well as higher HMO levels [23••, 59]. Several maternal factors may affect the breast milk microbiota, including maternal weight and mode of delivery [60].

\section{Areas for Future Research in Breast Milk and Infantile Diarrhea}

Much has been learned in recent years about the mechanism by which breastfeeding improves child health and survival. However, there are still multiple developmental areas to use these insights to improve pediatric care. Continued research in breast milk will help identify protective compounds and mechanisms in order to promote breastfeeding and the use of human milk in general, but also may help develop new strategies to fight infectious diseases in other non-breastfeeding populations. Here we highlight some priorities in human milk research and diarrhea.

- Breastfeeding promotion: Investigate the effectiveness of culture-appropriate health education and public health messages for breastfeeding promotion and to determine which communication strategies are best to spread knowledge and generate change in behavior in developing countries. These health education interventions should be aimed at increasing breastfeeding rates and adequate breastfeeding practices following the three key components of WHO's recent recommendations: timely initiation (within $1 \mathrm{~h}$ of birth) of breastfeeding, exclusive breastfeeding up to the age of 6 months, and continued breastfeeding through 24 months [61].

- Observational longitudinal studies to determine the natural protection of specific breast milk components against infantile diarrhea and pathogen-specific protection (i.e., lactoferrin concentrations, HMO types, secretory antibodies and other glycoconjugates)

- Study the genetic determinants responsible for the variability in human milk composition, such as single nucleotide polymorphisms (SNPs) in specific genes (e.g., lactoferrin). This may help determine which infants may benefit from additional protections if its own mothers' milk lacks adequate concentrations (i.e., lactoferrin), or types (i.e., HMO types) of these protective factors.

- Clinical and laboratory research comparing lactoferrin types (human, bovine, recombinant human) to determine which type is the best candidate for clinical trials.

- Clinical trials to determine the effect of specific milk components, in the prevention and treatment of acute and prolonged diarrhea in susceptible young infants and in special populations.

\section{Conclusions}

Breast milk is a rich source of immune and non-immune components that give protection to children against enteropathogens. Recent studies have found significant increases in diarrhea morbidity and mortality in children when receiving suboptimal breastfeeding. There is a large body of evidence based on in vitro and in vivo studies on the protective effect of each milk components and the mechanisms associated to this protection. However, few clinical studies have translated this knowledge to improve pediatric care using individual isolated components as medicines. Although there is clinical evidence of protection of specific milk components, due to the immunologic complexity of human milk, the mixture of all components, that is to say the use of whole milk, is the most beneficial for small infants. Despite the well-known protective effect of breastfeeding and the WHO recommendations, exclusive breastfeeding rates continue to be low, particularly in developing countries. Therefore, it is necessary to continue implementing educational strategies to improve breastfeeding practices, thereby, decreasing the burden of 
diarrheal disease and its negative effects on growth and development.

\section{Compliance with Ethics Guidelines}

Conflict of Interest Christie G. Turin and Theresa J. Ochoa declare that they have no conflict of interest

Human and Animal Rights and Informed Consent This article does not contain any studies with human or animal subjects performed by any of the authors.

\section{References}

Papers of particular interest, published recently, have been highlighted as:

- Of importance

•- Of major importance

1. Liu L, Johnson HL, Cousens S, et al. Global, regional, and national causes of child mortality: an updated systematic analysis for 2010 with time trends since 2000. Lancet. 2012;379:2151-61. The Child Health Epidemiology Reference Group (CHERG) of WHO and UNICEF has systematically estimated the distribution of child mortality by cause at the regional and global level for year 2010. Neonatal complications, pneumonia and diarrhea are the leading causes of death worldwide.

2. Bhutta ZA, Black RE. Global maternal, newborn, and child healthso near and yet so far. N Engl J Med. 2013;369:2226-35.

3. Guerrant RL, Oriá RB, Moore SR, et al. Malnutrition as an enteric infectious disease with long-term effects on child development. Nutr Rev. 2008;66:487-505.

4. Walker CLF, Friberg IK, Binkin N, et al. Scaling up diarrhea prevention and treatment interventions: a lives saved tool analysis. PLoS Med. 2011;8:e1000428.

5. Bhutta ZA, Das JK, Walker N, et al. Interventions to address deaths from childhood pneumonia and diarrhoea equitably: what works and at what cost? Lancet. 2013;381:1417-29. Systematic review of studies showing the effectiveness of various interventions (preventive and therapeutic) against childhood diarrhea and pneumonia, and relevant delivery strategies. Breastfeeding is one of the most cost-effective interventions to lessen diarrhea burden.

6. Jones G, Steketee RW, Black RE, et al. How many child deaths can we prevent this year? Lancet. 2003;362:65-71.

7. Morrow AL, Rangel JM. Human milk protection against infectious diarrhea: implications for prevention and clinical care. Semin Pediatr Infect Dis. 2004;15:221-8.

8.• Lamberti LM, Fischer Walker CL, Noiman A, et al. Breastfeeding and the risk for diarrhea morbidity and mortality. BMC Public Health. 2011;11:S15. A systematic review of 18 clinical studies found a significant positive effect of breastfeeding against diarrhea incidence, prevalence, hospitalization and mortality. The degree of protection is depended on the level of breastfeeding exposure. This supports current $W H O$ recommendation for exclusive breastfeeding during the first 6 months of life as a key child survival intervention.

9. Arifeen S, Black RE, Antelman G, et al. Exclusive breastfeeding reduces acute respiratory infection and diarrhea deaths among infants in Dhaka slums. Pediatrics. 2001;108:E67.

10. Lim SS, Vos T, Flaxman AD, et al. A comparative risk assessment of burden of disease and injury attributable to 67 risk factors and risk factor clusters in 21 regions, 1990-2010: a systematic analysis for the Global Burden of Disease Study 2010. Lancet. 2012;380: 2224-60. This study evaluated the leading risk factors that increase mortality and disability worldwide. Suboptimal breastfeeding showed a significant negative effect on children health, which was measure by deaths and disability-adjusted life years.

11.• Black RE, Victora CG, Walker SP, et al. Maternal and child undernutrition and overweight in low-income and middle-income countries. Lancet. 2013;382:427-51. Systematic evaluation of the nutritional status and factors associated with undernutrition of mothers and children from low and middle income countries. Suboptimal breastfeeding increased the risk of death in children younger than 2 years of age.

12.• Roberts TJ, Carnahan E, Gakidou E. Can breastfeeding promote child health equity? A comprehensive analysis of breastfeeding patterns across the developing world and what we can learn from them. BMC Med. 2013;11:254. Analysis of breastfeeding practices in 137 developing countries from 1990 to 2010. Researchers found a wide range of breastfeeding prevalence and an increase in disability-adjusted life years secondary to suboptimal breastfeeding.

13. World Health Organization. The optimal duration of exclusive breastfeeding: report of an expert consultation. Geneva: World Health Organization; 2001.

14. Section on Breastfeeding. Breastfeeding and the use of human milk. Pediatrics 2012, 129:e827-841.

15. Haroon S, Das JK, Salam RA, et al. Breastfeeding promotion interventions and breastfeeding practices: a systematic review. BMC Public Health. 2013;13:1-18. Systematic review of 110 randomized studies on the effectiveness of various intervention and delivery strategies to increase rates of exclusive breastfeeding.

16. Imdad A, Yakoob MY, Bhutta ZA. Effect of breastfeeding promotion interventions on breastfeeding rates, with special focus on developing countries. BMC Public Health. 2011;11:S24.

17. Lawrence RM. Circumstances when breastfeeding is contraindicated. Pediatr Clin North Am. 2013;60:295-318.

18. Bosch AM, Grootenhuis MA, Bakker HD, et al. Living with classical galactosemia: health-related quality of life consequences. Pediatrics. 2004;113:e423-8.

19. Horvath T, Madi BC, Iuppa IM, et al. Interventions for preventing late postnatal mother-to-child transmission of HIV. Cochrane Database Syst Rev. 2009;1, CD006734.

20. Gonçalves DU, Proietti FA, Ribas JGR, et al. Epidemiology, treatment, and prevention of human T-cell leukemia virus type 1associated diseases. Clin Microbiol Rev. 2010;23:577-89.

21.• Ballard O, Morrow AL. Human Milk Composition. Pediatr Clin North Am. 2013;60:49-74. Very comprehensive review of the nutrients and bioactive factors present in human milk; the factors associated with the variability on human milk composition, and the impact of storage and pasteurization on milk components.

22. Smilowitz JT, O'Sullivan A, Barile D, et al. The human milk metabolome reveals diverse oligosaccharide profiles. J Nutr. 2013;143:1709-18.

23.• Bode L. Human milk oligosaccharides: every baby needs a sugar mama. Glycobiology. 2012;22:1147-462. Comprehensive review on human milk oligosaccharides structure, composition, variation, biosynthesis, and postulated beneficial effects for the breastfed neonate: antiadhesive antimicrobial, immune modulation, NEC protection, brain development among others.

24. Morrow AL, Ruiz-Palacios GM, Jiang X, et al. Human-milk glycans that inhibit pathogen binding protect breast-feeding infants against infectious diarrhea. J Nutr. 2005;135:1304-7.

25. Newburg DS, Ruiz-Palacios GM, Morrow AL. Human milk glycans protect infants against enteric pathogens. Annu Rev Nutr. $2005 ; 25: 37-58$. 
26. Zivkovic AM, German JB, Lebrilla CB, et al. Human milk glycobiome and its impact on the infant gastrointestinal microbiota. Proc Natl Acad Sci. 2011;108:4653-8.

27. Ruiz-Palacios GM, Cervantes LE, Ramos P, et al. Campylobacter jejuni binds intestinal $\mathrm{H}(\mathrm{O})$ antigen (Fuc alpha 1, 2Gal beta 1, 4GlcNAc), and fucosyloligosaccharides of human milk inhibit its binding and infection. J Biol Chem. 2003;278:14112-20.

28. Morrow AL, Ruiz-Palacios GM, Altaye M, et al. Human milk oligosaccharides are associated with protection against diarrhea in breast-fed infants. J Pediatr. 2004;145:297-303.

29. Coppa GV, Zampini L, Galeazzi T, et al. Human milk oligosaccharides inhibit the adhesion to Caco-2 cells of diarrheal pathogens: Escherichia coli, Vibrio cholerae, and Salmonella fyris. Pediatr Res. 2006;59:377-82.

30. Cano-Mancera R, López-Revilla R. Inhibition of the adhesion of Entamoeba histolytica trophozoites to human erythrocytes by carbohydrates. Parasitol Res. 1987;74:18-22.

31. Brandtzaeg P. The mucosal immune system and its integration with the mammary glands. J Pediatr. 2010;156:S8-15.

32.• Peterson R, Cheah WY, Grinyer J, et al. Glycoconjugates in human milk: Protecting infants from disease. Glycobiology. 2013;23: 1425-38. Comprehensive review of the variety of human milk glycoconjugates, their function and the mechanism for preventing children's diseases.

33. Durand D, Ochoa TJ, Bellomo SME, et al. Detection of secretory immunoglobulin A in human colostrum as mucosal immune response against proteins of the type III secretion system of Salmonella, Shigella and enteropathogenic Escherichia coli. Pediatr Infect Dis J. 2013;32:1122-6.

34. Korpe PS, Liu Y, Siddique A, et al. Breast milk parasite-specific antibodies and protection from amebiasis and cryptosporidiosis in Bangladeshi infants: a prospective cohort study. Clin Infect Dis. 2013;56:988-92.

35. Berlutti F, Pantanella F, Natalizi T, et al. Antiviral properties of lactoferrin-a natural immunity molecule. Mol Basel Switz. 2011;16:6992-7018

36.• Vogel HJ. Lactoferrin, a bird's eye view. Biochem Cell Biol. 2012;90:233-44. Review of lactoferrin structure and beneficial functional properties: antimicrobial, anti-cancer, immunoregulato$r y$, and other effects on human health.

37. Brock JH. Lactoferrin-50 years on. Biochem Cell Biol. 2012;90: 245-51.

38. Baker HM, Baker EN. A structural perspective on lactoferrin function. Biochem Cell Biol. 2012;90:320-8.

39. Ochoa TJ, Cleary TG. Effect of lactoferrin on enteric pathogens. Biochimie. 2009;91:30-4.

40. Gomez HF, Ochoa TJ, Herrera-Insua I, et al. Lactoferrin protects rabbits from Shigella flexneri-induced inflammatory enteritis. Infect Immun. 2002;70:7050-3.

41. Mosquito S, Ochoa TJ, Cok J, et al. Effect of bovine lactoferrin in Salmonella ser. Typhimurium infection in mice. Biometals. 2010;23:515-21.

42. Rivera FP, Medina AM, Bezada S, et al. Bovine lactoferrin decreases cholera-toxin-induced intestinal fluid accumulation in mice by ganglioside interaction. PloS One. 2013;8:e59253.

43. Lingappan K, Arunachalam A, Pammi M. Lactoferrin and the newborn: current perspectives. Expert Rev Anti Infect Ther. 2013;11:695-707.

44. Ochoa TJ, Pezo A, Cruz K, et al. Clinical studies of lactoferrin in children. Biochem Cell Biol. 2012;90:457-67. Review of 19 clinical studies evaluating the effect human or bovine lactoferrin on various health outcomes in children. Three studies focused on prevention and treatment of enteric infections and possible mechanisms of protection.

45. Egashira M, Takayanagi T, Moriuchi M, et al. Does daily intake of bovine lactoferrin-containing products ameliorate rotaviral gastroenteritis? Acta Paediatr. 2007;96:1242-4.

46. Zavaleta N, Figueroa D, Rivera J, et al. Efficacy of rice-based oral rehydration solution containing recombinant human lactoferrin and lysozyme in Peruvian children with acute diarrhea. J Pediatr Gastroenterol Nutr. 2007;44:258-64.

47. Ochoa TJ, Chea-Woo E, Campos M, et al. Impact of lactoferrin supplementation on growth and prevalence of Giardia colonization in children. Clin Infect Dis. 2008;46:1881-3.

48. Ochoa TJ, Chea-Woo E, Baiocchi N, et al. Randomized doubleblind controlled trial of bovine lactoferrin for prevention of diarrhea in children. J Pediatr. 2013;162:349-56. Randomized trial of bovine lactoferrin supplementation in children with intense diarrhea surveillance. There was no effect on diarrhea incidence; however, there was a significant decrease in diarrhea longitudinal prevalence and severity, although not clinically significant at the dose studied.

49. Hill DR, Rho HK, Kessler SP, et al. Human milk hyaluronan enhances innate defense of the intestinal epithelium. J Biol Chem. 2013;288(40):29090-104.

50. Liu B, Yu Z, Chen C, et al. Human milk mucin 1 and mucin 4 inhibit Salmonella enterica serovar Typhimurium invasion of human intestinal epithelial cells in vitro. J Nutr. 2012;142:1504-9.

51. Newburg DS, Peterson JA, Ruiz-Palacios GM, et al. Role of human-milk lactadherin in protection against symptomatic rotavirus infection. Lancet. 1998;351:1160-4.

52. Asensi MT, Martínez-Costa C, Buesa J. Anti-rotavirus antibodies in human milk: quantification and neutralizing activity. J Pediatr Gastroenterol Nutr. 2006;42:560-7.

53. Fernandez L, Langa S, Martin V, Maldonado A, Jimenez E, Martin $\mathrm{R}$, et al. The human milk microbiota: origin and potential roles in health and disease. Pharmacol Res Off J Ital Pharmacol Soc. 2013;69:1-10

54. Latuga MS, Stuebe A, Seed PC. A review of the source and function of microbiota in breast milk. Semin Reprod Med. 2014;32:68-73.

55. Hunt KM, Foster JA, Forney LJ, et al. Characterization of the Diversity and Temporal Stability of Bacterial Communities in Human Milk. PLoS One. 2011;6:e21313.

56. Martín R, Heilig GHJ, Zoetendal EG, et al. Diversity of the Lactobacillus group in breast milk and vagina of healthy women and potential role in the colonization of the infant gut. J Appl Microbiol. 2007;103:2638-44.

57. Martin R, Jimenez E, Heilig H, et al. Isolation of Bifidobacteria from Breast Milk and Assessment of the Bifidobacterial Population by PCR-Denaturing Gradient Gel Electrophoresis and Quantitative Real-Time PCR. Appl Environ Microbiol. 2009;75:965-9.

58. Kawano A, Emori Y. Changes in maternal secretory immunoglobulin a levels in human milk during 12 weeks after parturition. Am J Hum Biol. 2013;25:399-403.

59. Gabrielli O, Zampini L, Galeazzi T, et al. Preterm milk oligosaccharides during the first month of lactation. Pediatrics. 2011;128: e1520-31.

60. Cabrera-Rubio R, Collado MC, Laitinen K, et al. The human milk microbiome changes over lactation and is shaped by maternal weight and mode of delivery. Am J Clin Nutr. 2012;96:544-51.

61. World Health Organization. Global strategy on infant and young child feeding. Geneva: World Health Organization; 2003. 